\title{
Driving societal changes towards an electromobility future
}

\author{
Pierluigi Coppola $^{1} \cdot$ Elisabete Arsenio $^{2}$
}

Published online: 11 November 2015

(C) The Author(s) 2015. This article is published with open access at SpringerLink.com

In Europe, road transport accounts for more than $71 \%$ of transport-related $\mathrm{CO}_{2}$ emissions with cars accounting for $73 \%$ of passenger traffic and the majority of greenhouse gas (GHG) related emissions. As part of the European strategies until 2030 and 2050, the European Commission's (EC) White Paper "Roadmap to a Single European Transport Area - Towards a competitive and resource efficient transport system" (EC [1]) points out the need to reduce GHG emissions from transport by at least $60 \%$ until middle of the century (2050) with respect to 1990 levels. Until 2030, the goal is for transport to reduce GHG emissions by around $20 \%$ with respect to 2008 levels. These decarbonisation targets impose significant economical, social and technological challenges.

When moving towards a low carbon economy, electromobility is seen as a key component of the agenda for sustainable mobility in Europe. By 2050, "conventionally fuelled vehicles" (vehicles using nonhybrid, internal combustion engines) are expected to be banned from cities giving place to other technological options such as electric vehicles powered by electricity. These can make use of renewable energy sources which will reduce the carbon footprint from a life cycle analysis perspective. Recently, the European Commission adopted the Strategic Energy Technology Plan (SET Plan) with the aim to ensure EU's leadership in the development and

This article is part of the Topical Collection on Driving Societal Changes towards an Electro-mobility Future

Pierluigi Coppola

coppola@ing.uniroma2.it

1 University of Rome "Tor Vergata”, Rome, Italy

2 ECTRI Transport Economics and Policies Group, Brussels, Belgium deployment of low carbon energy technologies in a costeffective way (EC [2]).

Battery electric vehicles (BEVs), together with plug-in hybrid vehicles, only account for $0.5 \%$ of the total new vehicle registrations in the EU-27 (EEA [4]). The use of renewable energy sources in the electricity production mix is important towards decarbonisation of the whole cycle: the Well-to-Wheel (WtW) cycle comprises the entire chain of production and usage of vehicles, the Well-to-Thank (WtT) and the Tank-to-Wheel (TtW) emissions. However, the use of renewable electricity in road transport remains low, around 13 kilotonnes oil equivalent (ktoe) (EEA [3]).

Several barriers can be found in the literature as possible factors to justify the above panorama. The paper by Bühne, et al. in this special issue presents an overview and points out the obstacles to overcome to assure a higher market penetration of electric vehicles. On the one hand, the additional costs due to development of smart grids, intelligent electricity distribution systems and other infrastructure-related costs represent an additional investment in terms of construction and maintenance costs for road developers and managers (typically the public administration). On the other hand, the high purchase costs of electric vehicles, the limits imposed by low availability of charging infrastructure and its coverage, the charging time and the limited battery range often do not cope with main requirements of drivers' daily activity patterns. Subjective factors such as those related to psychological aspects such as range anxiety and aesthetic variables have been proved to be a barrier, as well.

Addressing these barriers will be important to increase the competitiveness of e-vehicles in Europe as pointed out by Figenbaum, et al. However, the social competitiveness of BEVs will depend to some extent on the evolution of price of fuels and electricity as well as the battery costs. Also, the internalisation of external costs included in the 
above mentioned Transport White Paper strategy, such as those due to GHG emissions across the transport sector will play a central role in aligning market choices and sustainable mobility needs until 2030 and 2050 .

Without doubt, significant health benefits can be gathered from implementing cleaner fuels and vehicles, with positive impacts in the overall quality of life of citizens. However, possible side effects need to be accounted for in advance. Countries that used target measures or incentives for electric vehicles such as Norway, France, Germany, Denmark, Ireland and Sweden have seen the highest take-up of electric vehicles. Measures included, for example the exemption from $25 \%$ VAT and other purchase taxes for new cars, and the use of bus lanes. Within the present special issue, the article by Aarestrup and Odeck refers to the particular case of Norway, the country with the largest fleet of BEVs per capita in the world, where incentives had visible benefits but other adverse effects occurred as well. For example, the exemption from toll payments conducted to a reduction in toll revenues and providing access to bus lanes resulted in congestion effects.

Following the data by the Joint Research Centre of the EC, on average $13.2 \%$ of every household's budget is spent on transport. If the price per $\mathrm{km}$ of electric car driving is much lower (in comparison to other options), then the demand for travel (and number of $\mathrm{km}$ driven) will also increase so externalities due to congestion and land use impacts may turn critical in some contexts. An emerging research area is how to overcome risks of electromobility options and also to increase citizens' acceptability of more sustainable transport options and alternative fuelled vehicles. For this purpose more socioeconomic and behavioural research is needed to account for people's perceptions and preferences. In this special issue, Daubitz and Kawgan-Kagan's article focus on travellers' perceptions of electro-mobility for different charging options, whereas Kawgan-Kagan aims to identify social groups that require further attention in their mobility needs.
We believe that, in the current European policy context, it is a challenge to rethink the urban and metropolitan mobility systems in an integrated and sustainable way. The rise of new mobility services and operators, including organised ecar sharing services for functional trips and multimodal transport options (e.g. e-bikes and public transport) can act as catalysers in the process of creating more sustainable travel options for a wide range of users, including those who are most vulnerable in our society (e.g. low income, immigrants, elderly). In fact, start implementing new e-mobility services could increase access to electric vehicles on a large scale, with reduced costs facilitated by increasingly open data systems and intelligent environments in our cities. Overall, electromobility as an emerging low carbon transport option is understood as being part of an integrated package of socially inclusive solutions towards sustainable mobility in Europe.

Open Access This article is distributed under the terms of the Creative Commons Attribution 4.0 International License (http:// creativecommons.org/licenses/by/4.0/), which permits unrestricted use, distribution, and reproduction in any medium, provided you give appropriate credit to the original author(s) and the source, provide a link to the Creative Commons license, and indicate if changes were made.

\section{References}

1. EC- European Commission (2011). Roadmap to a Single European Transport Area - Towards a competitive and resource efficient transport system. White Paper, Communication 144 final, 28.03.2011

2. EC- European Commission (2015).Towards an Integrated Strategic Energy Technology (SET) Plan: Accelerating the European Energy System Transformation. Communication from the Commission 6317 final, 15.09.2015

3. EEA - European Environment Agency (2013). A closer look at urban transport. EEA Report n.11, Luxembourg

4. EEA - European Environment Agency (2014). Focusing on environmental pressures from long-distance transport. EEA report n. ${ }^{\circ} 7$, Luxembourg 